\title{
Innovative Application of Scrap-Tire Steel Cords in
}

\section{Concrete Mixes}

\author{
Ahmed N. Bdour \\ Civil Engineering Department, College of Engineering, University of Tabuk, Tabuk 71491, KSA
}

Received: March 28, 2011 / Accepted: December 21, 2011 / Published: April 20, 2012.

\begin{abstract}
Many researchers have investigated the use of recycled tire products in several traditional civil engineering materials. This research is exploring the use of steel cords, a by-product of the tire recycling process, in concrete mixes. Different concrete specimens were fabricated and tested in uniaxial compression and splitting tensile strength. The steel cords were substituted into the concrete mix in volumetric percentages of various ratios. Results show that mechanical properties of concrete made with steel cords are improved compared with concrete mix made with the traditional scrap-tires recycled material. Also, results show that even though the compressive strength is reduced when using steel cords, this reduction is minimal. When $2 \%$ of steel cords are used there is $18 \%$ increase in ductility. Moreover, splitting tensile tests show that concrete mixtures with any steel cords content have much greater toughness than control mixture. This mechanical property mix indicates an excellent potential application of modified concrete mix in structures that absorb large amount of energy.
\end{abstract}

Key words: Steel cords, scrap-tires, splitting tension strength, toughness.

\section{Introduction}

Currently, more than 9 million tires are generated in Kingdom of Saudi Arabia each year along with an existing 7 million tires stockpiled throughout the country. With the rapid development, higher living standards, and higher population growth, the quantities of scrap tires are expected to be increased sharply. The total number of abandoned scrap tires will be expected to reach 4 million in 2013.

Based on these facts, Kingdom of Saudi Arabia is facing an environmental problem related to the proper disposal of large-scale scrap tires. In order to properly dispose of these millions of tires, the use of innovative techniques to recycle them is important. Without the proper disposal of these waste tires, the resulting stockpiles would cause major health risks for the public and the environment.

Scrap tires were initially recycled for their rubber

Corresponding author: Ahmed N. Bdour, associate professor, Ph.D., main research fields: solid waste management, wastewater treatment and technologies and water resources planning and management. E-mail: bdour@ut.edu.sa. contents because of the environmental threats associated with; their proper disposal has attracted the attention of many researchers in the last years [1-5]. The history of recycling scrap tires can be tracked back to the 1940s [6].

Numerous uses of scrap tires have been introduced, including use in landfills, fuel and energy recovery, septic drain fields, subgrade fill, various rubber and plastic products, and asphalt binder [6]. Nowadays, with the advanced technologies by chipping tires and convalescing the steel cords, up to $99 \%$ of scrap tires can be recovered for recycling.

The typical composition of manufactured tires by weight is introduced in Table 1 . Two main products of the tire recycling are crumb rubber and tire chips (Fig. 1). Crumb rubber consists of particles ranging in size from 4.75 to less than $0.075 \mathrm{~mm}$, while tire chips are larger shredded rubber pieces, which contain a relatively small quantity of steel wires/cords (14\%-15\% by weight).

The steel weirs in the passenger tires are made of 
Table 1 Typical composition of manufactured tires by weight [7].

\begin{tabular}{lll}
\hline Composition (weight percentage) & Automobile tire & Truck tire \\
\hline Natural rubber & 14 & 27 \\
Synthetic rubber & 27 & 14 \\
Carbon black & 28 & 28 \\
Steel & $14-15$ & $14-15$ \\
Fabric, filler, accelerators and antiozonants & $16-17$ & $16-17$ \\
\hline
\end{tabular}

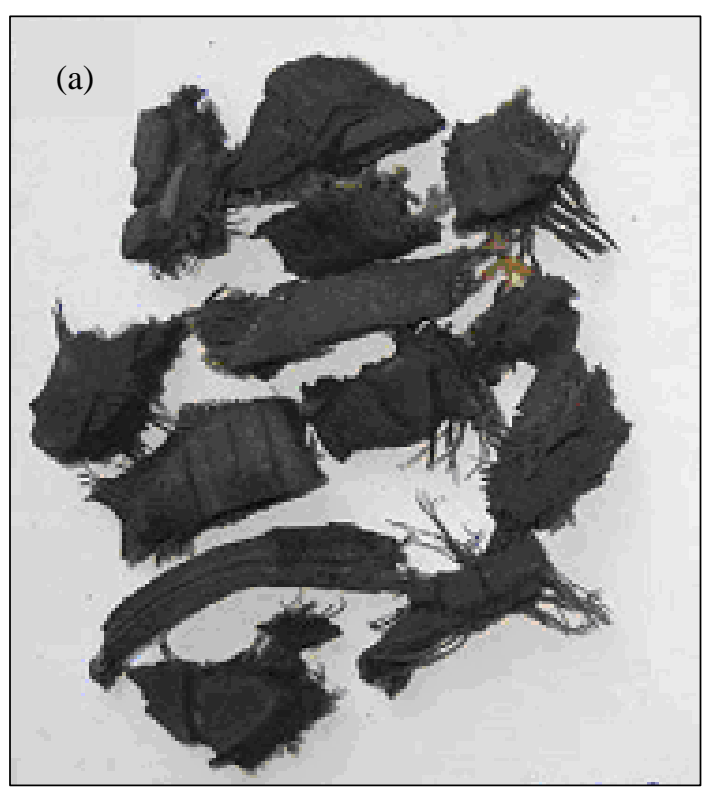

Fig. 1 (a) Tire crumbs; (b) steel cords.

high tensile strength steel wires (1,600-2,000 MPa) and are used to secure the tire in the rim. The recycled steel cords can be produced by the magnetic separation process, including short steel wires as well as wires covered by or embedded in rubber pieces (see Fig. 1). The difference between the tire chips and the steel cords is that the steel cords contain a much smaller quantity and size of rubber pieces and larger quantity of steel wires.

The use of crumb rubber and tire chips in concrete for recycling purposes has attracted a lot of attention. It has been reported that the replacement of coarse aggregate with waste tire chips in Portland cement concrete mixtures results in a significant increase of toughness and ductility [8]. On the contrary, losses in compressive strength of up to $85 \%$ have been reported when replacing the entire coarse aggregate fraction with tire chips [1], which makes the recycling of waste

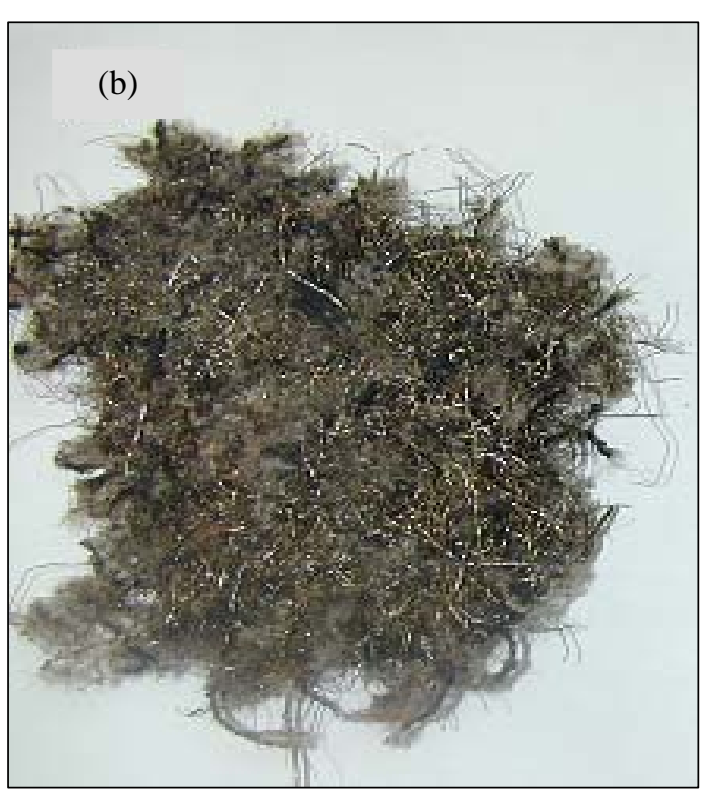

tire products in concrete unattractive.

However, the improved ductility and toughness could be very beneficial in several civil engineering applications. While the use of both crumb rubber and tire chips has been widely investigated, no study has explored the potential incorporation of waste steel cords.

The major problem facing the waste tire recycling industry in Kingdom of Saudi Arabia is that the market for used tires and tire shreds has not kept up with the growing backlog of discarded tires. Peering in mind, the rapid social, economical and environmental changes in Kingdom of Saudi Arabia stressed human society with unprecedented challenges. Thus, this industry seeks assistance to develop new products in order to attract new markets, locally and internationally. Moreover, more efforts are badly needed to help in changing customers' attitudes towards using scrap tires 
recycled material.

In an effort to support this industry, this paper demonstrates an experimental research investigating the use of waste tire steel cords in Portland cement concrete. Since recently the construction sector in Kingdom of Saudi Arabia is growing tremendously, therefore, it can be considered as a valuable potential consumer of the most recycled tire products in the construction materials. Ultimately, as an outcome of this research, the incorporation of steel cords in concrete could lead to a viable, environmental friendly engineering material with attractive properties.

\section{Methodology and Experimental Design}

For the purpose of this research, several concrete specimens were prepared and cured in accordance with ASTM C 192-00 and tested to assess structural and mechanical properties of the concrete mixes [9].

\subsection{Mix Design and Materials}

The raw materials used for the concrete mix are Ordinary Portland Cement Type I, fine and coarse aggregates taken from crushed limestone, and the steel cords provided by a local company, which are generated by the tire shredding process.

The fine aggregate had a specific gravity of 2.75 and fineness modulus of 2.9. The coarse aggregate had specific gravity of 2.65 with a maximum aggregate size of $14.6 \mathrm{~mm}$. The steel cords used in this study consisted of steel wires of varying lengths $(5-85 \mathrm{~mm})$ and diameters of $0.2-1.3 \mathrm{~mm}$ with an average density of approximately $2.7 \mathrm{~g} / \mathrm{cm}^{3}$, as well as rubber particle bonded to the wires. Table 2 shows the properties of recycled tire materials.

The control mix of concrete was designed with a mix ratio of cement/water/fine/coarse of 1.0:0.47:1.1:2.0 by weight. This control mix design yielded an average 28 day compressive strength of $39 \mathrm{MPa}$. A total of 87 concrete specimens have been fabricated mixing cement/fine/coarse/water then adding different percentages of steel cords to the concrete mix in volumetric percentages of $2 \%, 4 \%, 6 \%, 8 \%$ and $10 \%$.

\subsection{Specimen Preparation and Testing}

A total of 87 cylindrical concrete specimens were fabricated and cured according to ASTM C 192-00. For each mix, a minimum of fourteen cylindrical specimens were fabricated measuring $150 \mathrm{~mm} \times 300$ $\mathrm{mm}$. All specimens were tested at 28 days with a minimum of seven cylinders for compressive tests and seven cylinders for splitting tensile tests. All specimens were moist cured in a humidity controlled curing room.

For each concrete mix, slump and entrained air were performed and recorded at the casting time of the specimens. After the appropriate curing time, the compressive strength and splitting tensile test were performed, using a universal testing machine with a maximum load capacity of $300 \mathrm{kN}$, in accordance with procedures based on ASTM C39-03 and ASTM C 496-04, respectively. The compressive specimens were instrumented with a compressometer and LVDT (linear variable differential transformer) to recode deformation and a load cell to record the applied load. The indirect tensile strength data was obtained using LVDT measuring crosshead movement along with the load cell.

\section{Results and Discussion}

\subsection{Property of Concrete Slump, Air Content and Density}

Several properties of the fabricated concrete mixes were examined in this study. The effects of steel cords on the concrete mixtures are presented in Table 3 . The slump decreases at a constant rate as steel cord content increases. Although the slump decreased but the concrete mix remained workable. The steel cords had a tendency to interlock during the mixing process, leaving localized areas of high steel and rubber. The interlocking action of steel wires was more noticeable at higher steel cords ratios. In order to avoid this problem, the steel cords have been separated manually before being added to the mixer. 
Table 2 Properties of recycled tire materials.

\begin{tabular}{llll}
\hline Material & Tire chips & Crumb rubber & Steel cords \\
\hline Rubber(\%) & $95-99$ & $99-100$ & $35-75$ \\
Steel $(\%)$ & $1.5-8$ & 0 & $35-75$ \\
Density $\left(\mathrm{g} / \mathrm{cm}^{3}\right)$ & $0.8-1.6$ & $0.7-1.1$ & $1.5-3.9$ \\
\hline
\end{tabular}

Table 3 Summary of the experimental results.

\begin{tabular}{lllllll}
\hline $\begin{array}{l}\text { Steel bead } \\
\text { ratio }\end{array}$ & Slump $(\mathrm{cm})$ & $\begin{array}{l}\text { Density } \\
\left(\mathrm{kg} / \mathrm{m}^{3}\right)\end{array}$ & $\begin{array}{l}\text { Air content } \\
(\%)\end{array}$ & $\begin{array}{l}\text { Compressive } \\
\text { strength (MPa) }\end{array}$ & $\begin{array}{l}\text { Modulus of } \\
\text { elasticity (MPa) }\end{array}$ & $\begin{array}{l}\text { Splitting tension } \\
\text { strength (MPa) }\end{array}$ \\
\hline $0 \%$ & 17.1 & 2,349 & 1.6 & 38.8 & 27.72 & 2.74 \\
$2 \%$ & 16 & 2,335 & 1.5 & 38.1 & 24.55 & 2.6 \\
$4 \%$ & 14.6 & 2,321 & 1.5 & 34.5 & 24.80 & 2.54 \\
$6 \%$ & 13.7 & 2,308 & 1.8 & 32.1 & 24.96 & 2.43 \\
$8 \%$ & 11.6 & 2,298 & 1.9 & 29.4 & 19.68 & 2.31 \\
$10 \%$ & 10.2 & 2,280 & 2.1 & 22.1 & 15.89 & 2.01 \\
\hline
\end{tabular}

Air content of the concrete mixes was measured using ASTM standards. Results showed that air content variations were insignificant ranging from $1.6 \%$ to $2.1 \%$ as shown in Table 3.

This finding is consistent with results of other researchers [8]. This could be justified based on the fact that relatively small volume fraction, small sizes and lengths of steel cords were added. Also, experimental results show that steel cord content has a very small effect on the density of the concrete mixtures. The density of the control mix was 2,349 $\mathrm{kg} / \mathrm{m}^{3}$ while the mix containing $6 \%$ steel cords had a density of $2,308 \mathrm{~kg} / \mathrm{m}^{3}$.

\subsection{Property of Concrete Strength}

The uniaxial compression tests confirm that the addition of steel cords does not enhance the compressive strength of concrete mixtures. Results indicate that retained compressive strength for different steel cord ratios varied from $98 \%$ to $71 \%$ of the control specimen, while the retained tensile strength varied from $95 \%$ to $73 \%$ of the control specimen. The larger the amount of steel cords in the mix, the higher the losses in compressive strength and tensile strength. The experimental results are shown in Fig. 2, where the percent of the retained compressive strength is presented versus the steel cord content.

The reduction in compressive strength can be explained based on the fact that steel cords contain both

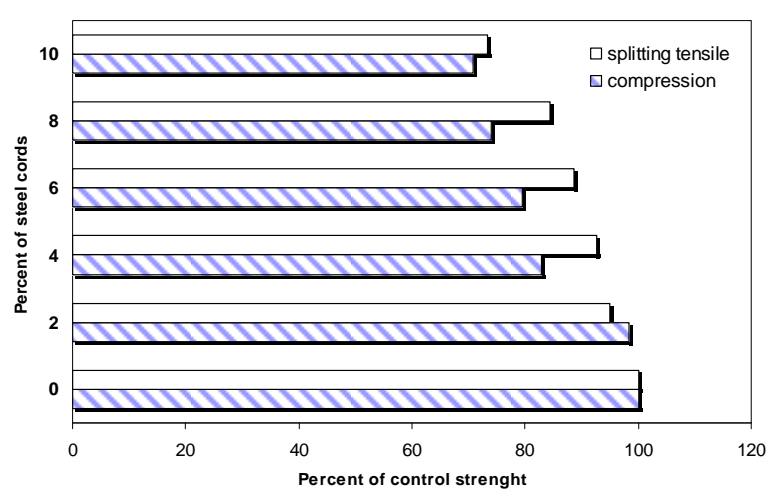

Fig. 2 Retained compressive strength and splitting tensile strength versus steel cord ratio.

steel wires and rubber particle. Rubber particles are much softer than the surrounding cement matrix, which acts as stress concentrator and causes cracking at the rubber-cement interface upon loading. These cracks then propagate through the specimen and lead to a loss in strength and ultimately to failure. Moreover, the replacement of hard, dense aggregate with a less dense rubber will cause loss in strength because the strength of concrete is highly dependent on paste quality and aggregate properties.

\subsection{Property of Concrete Stress-Strain Curve}

Although a reduction in the compressive was noticeable when steel cords are used but not strong as the effect of crump rubber, Batayneh et al. [10] reported that an addition of $40 \%$ of crump rubber to concrete mixes leads to a loss of $50 \%$ of the 


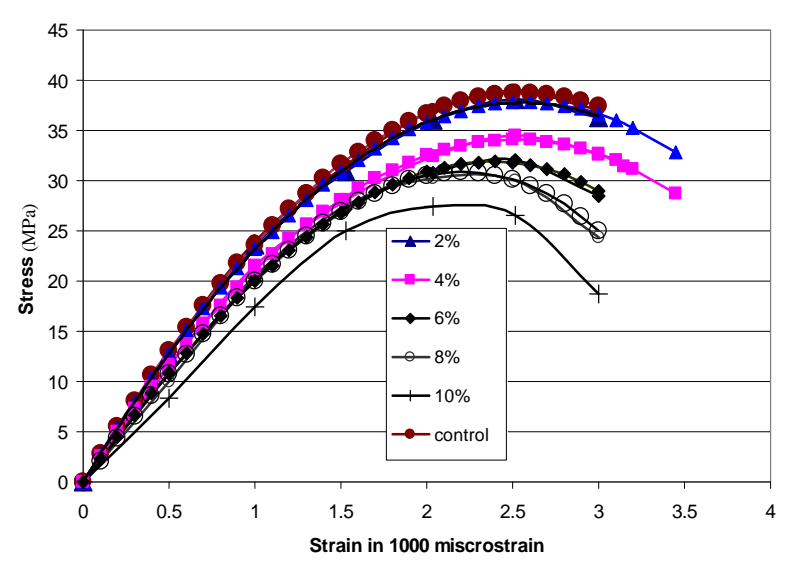

Fig. 3 Relationship between compressive stress and strain for different steel cord ratios.

compressive strength. However, the examination of stress-strain curve shows that an increase in ductility can be seen for the $2 \%$ and $4 \%$ steel cord contents, as shown in Fig. 3. The increase was approximately 15\% where the reduction in compressive strength was $5 \%$ and $17 \%$, respectively as indicated in Fig. 2.

On the contrary, for $6 \%, 8 \%$ and $10 \%$ of steel cord ratios there was no increase in ductility. These findings can be explained based on fact that steel cords contain much smaller quantity and size of rubber and large volume of steel wires, therefore when they incorporated with concrete mixtures they act as reinforcement and resist crack growth, and therefore allow for an increased ductility. Herein, it should be mentioned that the incorporation of relatively small quantities of steel cords, up to $4 \%$, could increase concrete ductility by $15 \%$ without causing a significant loss of compressive strength.

Moreover, the load deflection curves analysis indicated that the steel cords of specimens exhibited much higher toughness and underwent a significant deformation without collapse, as shown in Fig. 4. The steel cords act similar to the steel fiber which reinforce concrete and permit the concrete specimen to exhibit large deformations while resisting significant post-cracking loads. This phenomenon was clear during the splitting tensile test, after the initial cracking, the steel wires control the cracking behavior of

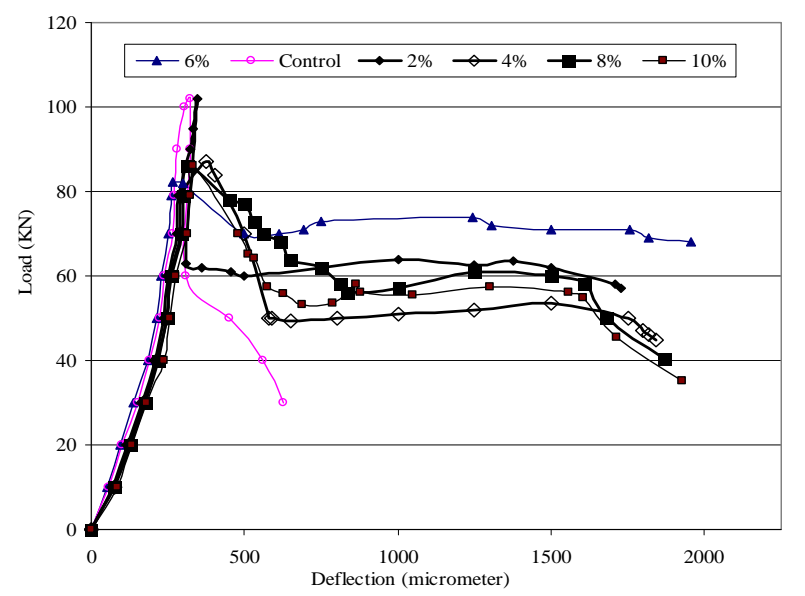

Fig. 4 Relationship between splitting tension load and deflection.

concrete specimen and alter the post cracking. Also, it can be seen from Fig. 4 that the initial slope of the concrete specimens with steel cords are slightly steeper than the slope of the control mix.

This can be explained by the tension stiffening which is very common in steel fiber reinforced concrete. After the initial cracking of the matrix, the steel fibers hold the micro cracking mechanism and limit crack propagation. It seems that the existence of steel wires causes redistribution of load. Thus, the toughness and ductility are significantly improved. The high toughness of concrete mix indicates an excellent potential application in structures that absorb large amount of energy. Also, results showed that mechanical properties of concrete made with steel cords were improved compared with concrete mix made with the addition of crump rubber or rubber chips.

\section{Conclusions}

The experimental results demonstrated in this study show that there is a great potential for the incorporation of steel cords in concrete mixes. Based on these results, the following can be concluded:

- The modified concrete mixed recycled steel cords performed satisfactory. The incorporation of steel cords slightly reduces the density of concrete mixes when compared to the control mix. The slump 
decreases at a constant rate as steel cord content increases;

- Although the slump decreased, the concrete mix remained workable. Concrete mixtures can be made containing small volume fractions of waste tire cords; the mixtures are workable up to $4 \%$;

- Although the addition of steel cords to the concrete mixtures results in a reduction of the compressive strength, this reduction is minimal when $2 \%$ of steel cords are used while there is $18 \%$ increase in ductility. Thus, it is recommended not to use the modified concrete mix with high percentages of steel cords in structures that require high strength;

- Splitting tensile tests show that concrete mixtures with any steel cords content have much greater toughness than control mixture. This mechanical property mix indicates an excellent potential application of modified concrete mix in structures that absorb large amount of energy. Also, results showed that mechanical properties of concrete made with steel cords were improved compared with concrete mix made with the addition of crump rubber or rubber chips;

- Steel wires act as reinforcement in concrete and permit the concrete specimen to exhibit large deformations while resisting significant post-cracking loads.

\section{Acknowledgments}

The author of this work would like to thank the Deanship of Graduate Studies and Scientific Research at the Hashemite University for their financial support. Also, special thanks and gratitude to Municipality of
Tabuk Region for their technical assistance and for providing us with all necessary equipment and facilities needed to conduct the experimental part of this project.

\section{References}

[1] O. Celik, C. Atis, Laboratory comparison of the crumb rubber and SBS, Construction and Building Materials Journal 25 (8) (2011) 3204-3212.

[2] Y. Yetkin, Field performance comparison of asphalt crack-filling materials: Hot pour versus cold pour, Canadian Journal of Civil Engineering 34 (4) (2007) 505-512.

[3] D. MacLeod, S. Ho, R. Wirth, L. Zanzotto, Study of crumb rubber materials as paving asphalt modifiers, Canadian Journal of Civil Engineering 34 (10) (2007) 1276-1288.

[4] A. Ghaly, J. Cahill, Correlation of strength, rubber content, and water to cement ratio in rubberized concrete, Canadian Journal of Civil Engineering 32 (6) (2005) 1075-1081.

[5] O. Svec, R. Veizer, Note on structural strength of asphalt rubber concrete developed through the stone mastic asphalt concept, Canadian Journal of Civil Engineering 23 (1) (1996) 295-301.

[6] W. Cao, Study on properties of recycled tire rubber modified asphalt mixtures using dry process, Construction and Building Materials Journal 21 (2007) 1011-1015.

[7] Y. Huang, R. Bird, O. Heidrich, A review of the use of recycled solid waste materials in asphalt pavements, Resources, Conservations and Recycling Journal 52 (2007) 58-73.

[8] R. Siddique, T. Naik, Properties of concrete containing scrap-tire rubber-An overview, Waste Management Journal 24 (2004) 563-569.

[9] ASTM Standard Practice for Making and Curing Concrete Test Specimens in the Laboratory, American Society for Testing and Materials, West Conshohocken, PA, USA, 2006.

[10] M. Batayneh, I. Marie, I. Asi, Promoting the use of crump rubber concrete in developing countries, Waste Management Journal 35 (9) (2007) 124-131. 